\title{
Clinical Determinants of Left Ventricular Ejection Fraction Deterioration in Patients Suffered From Complete Left Bundle Branch Block
}

\author{
Mohammad Hashemi Jazi ${ }^{1}$; Peyman Nilforoush ${ }^{1}$; Mojgan Gharipour ${ }^{1,{ }^{*}}$; Azadeh Batvandi ${ }^{1}$; \\ Robabeh Mohammadi ${ }^{1}$; Roya Najafi ${ }^{1}$
}

${ }^{1}$ Isfahan Cardiovascular Research Institute, Isfahan University of Medical Sciences, Isfahan, IR Iran

${ }^{*}$ Corresponding Author: Mojgan Gharipour, Isfahan Cardiovascular Research Institute, Isfahan University of Medical Sciences, Isfahan, IR Iran. Tel: +98-3116507448; +98-9131030177, E-mail: mojgangharipour@gmail.com

Received: January 13, 2014; Revised: August 31, 2014; Accepted: October 23, 2014

\begin{abstract}
Background: Recently, the deleterious effects of left bundle branch block(LBBB) on left ventricular systolic function have been taken into consideration.

Objectives: The present study aimed to identify underlying factors that predict left ventricular ejection fraction (LVEF) deterioration in patients suffered from complete LBBB.

Patients and Methods: In a retrospective case-control study, the data of 220 consecutive patients diagnosed with LBBB on their electrocardiograms were assessed. They were referred to Isfahan Heart Center in Isfahan Province, Iran in 2013. LVEF deterioration was defined as a decrease in LVEF at least 10\% between the baseline and follow-up echocardiography study. Thus, achieving the LVEF values $\leq$ $40 \%$ in patients with an initial $\mathrm{EF}$ of $>50 \%$ was considered LVEF deterioration.

Results: Among 220 patients, $40 \%$ of LBBB patients suffered LVEF deterioration within 3 months of initial assessment. The group with LVEF deterioration had higher male to female ratio, had higher NYHA score, and suffered more from systolic hypertension than another group. Those with coronary artery disease $(\mathrm{CAD})$ had also significantly lower LVEF than non-CAD ones. Adverse associations were revealed between systolic blood pressure and LVEF measurement $(\mathrm{r}=-0.193, \mathrm{P}=0.006)$ as well as between NYHA score and $\operatorname{LVEF}(\mathrm{r}=-0.215, \mathrm{P}=0.002)$. A multivariable logistic regression model showed that among baseline variables, male gender $(\mathrm{OR}=3.218, \mathrm{P}<0.001)$, history of systolic hypertension $(\mathrm{OR}=2.012, \mathrm{P}=0.029)$, higher NYHA score $(\mathrm{OR}=1.623, \mathrm{P}=0.005)$, and the presence of coronary artery disease $(\mathrm{OR}=2.475, \mathrm{P}=$ 0.028 ) could effectively predict LVEF deterioration in patients with $\mathrm{LBBB}$.

Conclusions: Male gender, history of hypertension, high NYHA score, and the presence of CAD predict LVEF deterioration in patients with LBBB.
\end{abstract}

Keywords:Bundle-Branch Block; Coronary Artery; Left Ventricular; Ejection Fraction

\section{Background}

New-onset LBBB leading to poor prognosis (even in asymptomatic patients) rises several questions concerning the importance of assessing relationship between this arrhythmic phenomenon and other functional and structural cardiac deterioration such as cardiac ischemic events (1), left ventricular hypertrophy (2), heart failure state (3), and left ventricular dysfunction (4). In this regard, the deleterious impact of LBBB on left ventricular systolic and diastolic function has been established even in patients without overt underlying heart disease (5). The poor prognosis of LBBB leading to noted cardiovascular events can be associated with an increased mortality and morbidity, whatever the control population, even in healthier individuals. In this context, Framingham heart study showed a significant increase in mortality among patients with LBBB in comparison with normal subjects (6). In other large population studies, the appearance of LBBB was associated with increased risk of progressive heart failure, acute myocardial infarction, and atrioventricular block (7). Within the last decade, the deleterious effects of LBBB on left ventricular systolic and diastolic function have been taken into consideration. Delaying left ventricular systolic and diastolic function indicated by reduced left ventricular ejection fraction (LVEF) may be explained by septal motion abnormality that has been shown by some authors $(8,9)$. However, the underlying factors of reduced LVEF in LBBB patients have not been clearly determined. Meanwhile, by identifying and controlling baseline triggering factors affecting LVEF decline in these patients, prevention of the progressive left ventricular dysfunction can be effectively facilitated.

\section{Objectives}

The present study aimed to identify underlying factors that predict LVEF deterioration in patients who suffered from complete LBBB.

Copyright ( ) 2014, Iranian Red Crescent Medical Journal. This is an open-access article distributed under the terms of the Creative Commons Attribution-NonCommercial 4.0 International License (http://creativecommons.org/licenses/by-nc/4.0/) which permits copy and redistribute the material just in noncommercial usages, provided the original work is properly cited. 


\section{Patients and Methods}

\subsection{Study Population}

In this retrospective case-control study, the data of 220 consecutive patients diagnosed with LBBB on their electrocardiograms were assessed. They were referred to Isfahan Heart center, as a general referral hospital in Isfahan Province, Iran from July to September 2013. LBBB was diagnosed according to the definition criteria of the New York Heart Association as "QRS interval $\geq 120 \mathrm{~ms}$, notched, wide and predominant $\mathrm{R}$ waves in leads I, aVL, V5, and V6, notched and broad S waves in V1 and V2 with absent or small $\mathrm{R}$ waves, notching or a plateau in the mid-QRS wave, ventricular activation time $>50 \mathrm{~ms}$ at the onset of the QRS interval, M-shaped QRS variants with occasionally wide $R$ waves in V5 and V6, no initial Q wave over the left precordium and absence of pre-excitation" (10). The diagnosis of LBBB was performed by a cardiologist blinded to the study design. The main inclusion criteria included the presence of LBBB, the existence of at least two consecutive echocardiography studies with a minimum follow-up of 3 months and a reliable left ventricular ejection fraction (LVEF), and a LVEF > 50\% at initial assessment. All patients who suffered ischemic events or underwent any cardiac interventions between the two echocardiography assessments were excluded from the study. Because none of the patients experienced these events, 220 initially included patients were finally assessed. The study met the requirements for a waiver of informed consent from the institutional review board at Isfahan University of Medical Sciences. In this study, LVEF deterioration was defined as a decrease in LVEF at least 10\% between the baseline and follow-up echocardiography study. Thus, achieving the LVEF values $\leq 40 \%$ in patients with an initial EF of $>50 \%$ was considered as LVEF deterioration. LVEF was visually estimated in the apical 4 - and 2-chamber views (11).

\subsection{Data Collection}

Data were collected by reviewing hospital recorded files, including demographic characteristics and clinical data on cardiovascular risk factors such as current smoking history (patients regularly smoke a tobacco products one or more times per day or have smoked in the last 30 days prior to admission) (12), hypercholesterolemia (total cholesterol $\geq 5.0 \mathrm{mmol} / \mathrm{L}$, HDLcholesterol $\geq 1.0 \mathrm{mmol} / \mathrm{L}$ in men, or $\geq 1.1 \mathrm{mmol} / \mathrm{L}$ in women, and triglycerides $\geq 2.0 \mathrm{mmol} / \mathrm{L}$ ) (13), hypertension (systolic blood pressure $\geq 140 \mathrm{mmHg}$ and/ or diastolic $\geq 90 \mathrm{mmHg}$ and/or on antihypertensive treatment), diabetes mellitus (symptoms of diabetes plus at least one of the following parameters: plasma glucose concentration $\geq 11.1 \mathrm{mmol} / \mathrm{L}$, fasting plasma glucose $\geq 7.0 \mathrm{mmol} / \mathrm{L}$, and 2-hpp $\geq 11.1 \mathrm{mmol} / \mathrm{L}$ ) (14), and the New York Heart Association (NYHA) functional classification for assessing heart failure state (15). Also, the angiography reports were assessed for determining the presence of CAD that was defined as $\geq 70 \%$ luminal diameter narrowing of a major epicardial artery or $\geq$ $50 \%$ narrowing of the left main coronary artery. Also, the number of involved coronary vessels and left main lesion were also assessed.

\subsection{Study Endpoints}

The study endpoint determined main baseline indicators, which associated with LVEF deterioration and could predict this phenomenon in complete LBBB patients.

\subsection{Statistical Analysis}

Sample size was determined at 95\% confidence interval, and 20\% precision. The expected prevalence of LV systolic function is $40.0 \%$ and $20.0 \%$ in those with and without LBBB, respectively from previous study (16), which eventually determined to be at least 220 patients. In this regard, the study power was also determined at 95.6\%. Results were reported as mean \pm standard deviation (SD) for the quantitative variables and percentages for the categorical variables. The groups were compared using the Student t test or Mann-Whitney U test regarding the continuous variables and the chi-square test (or Fisher exact test if required) for the categorical variables. The normality distribution of variables was assessed using the Kolmogorov-Smirnov test. Predictors exhibiting a statistically significant relation with LVEF deterioration in two groups were taken for a multivariable logistic regression analysis to investigate their independence as predictors. $\mathrm{P}$ values of 0.05 or less were considered statistically significant. All the statistical analyses were performed using SPSS version 19.0 (SPSS Inc., Chicago, IL, USA) for Windows.

\section{Results}

The echocardiography reports of 220 patients were reviewed for assessing LVEF deterioration. In this regard, 90 patients experienced deterioration (LVEF $\leq 40 \%$ ) compared to 130 patients without this event (LVEF > $40 \%)$. As shown in Table 1, the former group had higher male to female ratio, had higher NYHA score, and also suffered more from systolic hypertension than those without LVEF deterioration (mean systolic blood pressure, $134.80 \pm 23.48 \mathrm{mmHg}$ versus $127.53 \pm 20.41 \mathrm{mmHg}$ $\mathrm{P}=0.021$ ). The mean LVEF after follow-up period in men was $39.12 \pm 15.29 \%$ and in women was $47.98 \pm 14.53$ that was considerably lower in men. Also, mean LVEF in patients with and without systolic hypertension was 41.49 $\pm 16.30 \%$ and $47.92 \pm 13.40 \%$ with a significant discrepancy $(\mathrm{P}=0.002)$. Those with CAD was also significantly lower LVEF than non-CAD ones $(40.65 \pm 15.14 \%$ versus $46.66 \pm 12.26 \%, \mathrm{P}=0.004)$. In this regard, the patients 
with 3-vessel coronary involvement had considerably lower mean LVEF than the group with normal coronary vessels (34.49 $\pm 15.30 \%$ versus $46.66 \pm 15.26 \%, \mathrm{P}=0.004$ ) (Figure 1). However, no significant differences were observed between two groups in other variables such as average age, history of diabetes mellitus, hyperlipidemia, and smoking. The Pearson correlation coefficient analysis showed adverse associations between systolic blood pressure and LVEF measurement $(\mathrm{r}=-0.193, \mathrm{P}$ $=0.006)$ as well as between NYHA score and LVEF $(r=$ $0.215, \mathrm{P}=0.002)$ at follow-up time. A multivariable logistic regression model showed (Table 2 ) that among baseline variables, male gender $(\mathrm{OR}=3.218, \mathrm{P}<0.001)$, history of systolic hypertension $(\mathrm{OR}=2.012, \mathrm{P}=0.029)$, and higher NYHA score $(\mathrm{OR}=1.623, \mathrm{P}=0.005)$, and the presence of coronary artery disease $(\mathrm{OR}=2.475, \mathrm{P}=$ 0.028 ) could effectively predict LVEF deterioration in LBBB patients.

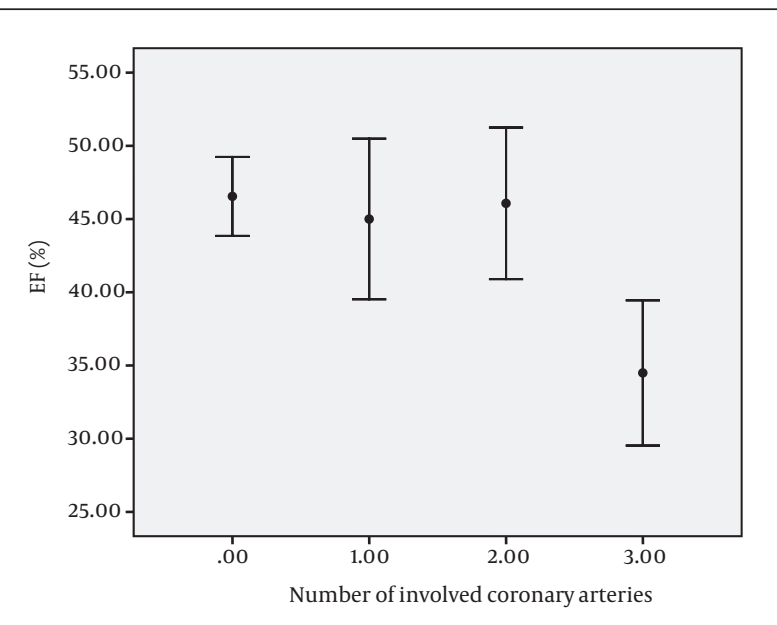

Figure 1. Association Between the Number of Involved Coronary Arteries and Left Ventricular Ejection Fraction in Patients With LBBB

Table 1. Baseline Characteristics and Clinical Data of Study Subjects a

\begin{tabular}{|c|c|c|c|}
\hline Characteristics & Group with LVEF $\leq 40 \%$ & Group with LVEF> $40 \%$ & PValue \\
\hline Male gender & $53(58.9)$ & $42(32.3)$ & $<0.001$ \\
\hline Age, y & $66.70 \pm 9.79$ & $65.62 \pm 10.41$ & 0.437 \\
\hline NYHA score & & & 0.011 \\
\hline I & $33(36.7)$ & $63(48.5)$ & \\
\hline II & $27(30.0)$ & $42(32.3)$ & \\
\hline III & $24(26.7)$ & $23(17.7)$ & \\
\hline IV & $6(6.7)$ & $2(1.5)$ & \\
\hline History of hypertension & $43(47.8)$ & $40(30.8)$ & 0.010 \\
\hline History of diabetes mellitus & $24(26.7)$ & $27(20.8)$ & 0.308 \\
\hline History of hyperlipidemia & $56(62.2)$ & $84(64.6)$ & 0.716 \\
\hline Current smoking & $16(17.8)$ & $24(18.5)$ & 0.895 \\
\hline Coronary artery disease & $46(51.1)$ & $46(35.4)$ & 0.020 \\
\hline Number of coronary involvement & & & 0.003 \\
\hline 0 & $43(47.8)$ & $82(63.1)$ & \\
\hline 1 & $12(13.3)$ & $16(12.3)$ & \\
\hline 2 & $9(10.0)$ & $19(14.6)$ & \\
\hline 3 & $26(28.9)$ & $13(10.0)$ & \\
\hline Left main lesion & $1(1.1)$ & $1(0.8)$ & 0.999 \\
\hline
\end{tabular}

${ }^{\mathrm{a}}$ Data are presented as No. (\%) and mean \pm SD.

Table 2. Multivariate Logistic Regression Modeling to Determine Main Determinants of LVEF Deterioration in Patients With LBBB a

\begin{tabular}{lccc}
\hline Characteristics & P Value & Odds Ratio & 95\% CI \\
\hline Male gender & $<0.001$ & 3.218 & $1.722-6.014$ \\
\hline Advanced age, $\mathbf{y}$ & 0.507 & 0.990 & $0.960-1.020$ \\
\hline Higher NYHA score & 0.005 & 1.623 & 2.012 \\
History of hypertension & 0.029 & 1.910 & $0.926-3.940$ \\
History of diabetes mellitus & 0.080 & 0.884 & $0.521-1.161$ \\
\hline History of hyperlipidemia & 0.625 & 0.324 & $0.202-1.654$ \\
\hline Smoking & 0.124 & 2.475 \\
\hline Coronary artery disease & 0.028 & $1.103-5.556$ \\
\hline
\end{tabular}

a Abbreviation: LBBB; left bundle branch block. 


\section{Discussion}

The present study aimed to assess LVEF deterioration in patients with LBBB and also tried to determine its main determinants helping prediction of this decline in patients with LBBB. The results showed that about $40 \%$ of LBBB patients would suffer LVEF deterioration within 3 months of initial assessment. Also, among all baseline parameters, hypertension status, male gender, high HYHA score, and presence of CAD could effectively predict LVEF deterioration in these patients. In fact, a significant link was revealed between interventricular dyssynchrony and LV dysfunction consistently with previous studies $(4,10,17)$.

Xiao et al. (16) reported a similar association of LBBB with deterioration of LV systolic function in patients with cardiomyopathy. Also, this association has been quantified by Zhou et al. (18) who showed that the LBBB-dependent activation abnormalities had a dominant effect on the deterioration of LV function. Moreover, Brunekreeft et al. confirmed a significant difference in left ventricular volumes, and LVEF between two groups with and without LBBB (19). Regarding deterioration of LVEF and similar to our study, Framingham study showed that the appearance of complete LBBB on a routine ECG was frequently associated with underlying hypertension and CAD. In Angheloiu study, history of congestive heart failure prior to baseline echocardiogram and high LV mass were associated with this phenomenon. According to these findings, it can be concluded that some underlying risk profile such as systolic hypertension, heart failure (assessed by NYHA classification), and cardiac ischemic event can predispose LBBB patients to LV dysfunction indicated by decline LVEF. In fact, as confirmed by some previous studies, some cardiovascular risk profile leading to elevated LV mass, shortening LV filling time, prolongation of relaxation times, increase in wall thickness, reduction of LV stroke index, and LV hypertrophy potentially result in lowering LVEF and consequently LV dysfunction in LBBB patients (20-22).

Regarding association between systolic hypertension and LVEF deterioration, this deteriorating effect can be mediated by the worsening effects of elevated systolic blood pressure on loading conditions of the ventricle, and also increase in afterload that produce a large decrease in stroke volume (23). Also, elevated blood pressure can increase cardiac workload, which leads to the development of left ventricular hypertrophy, LV mass, as well as relatively increased wall thickness. These abnormalities cause reduced LVEF. Also, decrease in LVEF may be due to systolic hypertension developing CAD that was also shown in our study as another main determinant (24).

With regard to the gender difference in left ventricular systolic function and reduced LVEF, the studies on a population-based sample aged 45 to 74 years showed that LVEF was less than the predefined partition value in $4.7 \%$ of women and in $16.7 \%$ of men in normal population, leading greater LV myocardial and chamber function in men than in women (25). Echocardiography assessments indicated higher velocity of mitral inflow early wave and the systolic velocity of the pulmonary vein flow as well as lower velocities of mitral annulus motion in the atrial and systolic phases in women, especially in postmenopausal state compared with men (26). This superiority has been also detected independent of hypertension condition as Celentano and colleagues indicated that clinically healthy hypertensive and normotensive women had higher LV chamber and midwall systolic function than men, independent of left ventricular geometry, body size, age and heart rate (27). These findings may also explain lower deterioration of LVEF in LBBB patients likely to healthy subjects.

The present study could effectively assess the left ventricular function status in those patients with LBBB and in this line, determined main determinants of LVEF deterioration in LBBB patients, especially in our population with a high prevalence of cardiovascular ischemic events. However, because of small available cases of LBBB in our center, further studies considering populationbased survey, including cases from other referral centers is recommended.

\section{References}

1. Angheloiu GO, Rahaby M, Starling RC, Angheloiu V, McNamara DM, Yamani MH, et al. Myocardial degradation and left bundle branch block predict conversion to low ejection fraction in heart failure with preserved systolic function. Congest Heart Fail. 2008;14(4):192-6.

2. Baranowski R, Malek L, Prokopowicz D, Spiewak M, Misko J. Electrocardiographic diagnosis of the left ventricular hypertrophy in patients with left bundle branch block: is it necessary to verify old criteria? Cardiol J. 2012;19(6):591-6.

3. Zannad F, Huvelle E, Dickstein K, Veldhuisen D, Stellbrink C, Køber L, et al. Left bundle branch block as a risk factor for progression to heart failure. Eur J Heart Fail. 2007;9(1):7-14.

4. Lee SJ, McCulloch C, Mangat I, Foster E, De Marco T, Saxon LA Isolated bundle branch block and left ventricular dysfunction. J Card Fail. 2003;9(2):87-92.

5. Baldasseroni S, Opasich C, Gorini M, Lucci D, Marchionni N, Perini G, et al. Left bundle-branch block is associated with increased 1-year sudden and total mortality rate in 5517 outpatients with congestive heart failure: a report from the Italian network on congestive heart failure. Am Heart J. 2002;143(3):398-405.

6. Schneider JF, Emerson Thomas H, Sorlie P, Kreger BE, McNamara PM, Kannel WB. Comparative features of newly acquired left and right bundle branch block in the general population: The framingham study. Am J Cardiol. 1981;47(4):931-40.

7. Eriksson P, Wilhelmsen L, Rosengren A. Bundle-branch block in middle-aged men: risk of complications and death over 28 years. The Primary Prevention Study in Goteborg, Sweden. Eur Heart J. 2005;26(21):2300-6.

8. Ozdemir K, Altunkeser BB, Danis G, Ozdemir A, Uluca Y, Tokac M et al. Effect of the isolated left bundle branch block on systolic and diastolic functions of left ventricle. J Am Soc Echocardiogr. 2001;14(11):1075-9.

9. Sadaniantz A, Saint Laurent L. Left ventricular Doppler diastolic filling patterns in patients with isolated left bundle branch block. Am J Cardiol. 1998;81(5):643-5.

10. Dolgin M. Nomenclature and criteria for diagnosis of diseases of the heart and great vessels. 9th ed: Little, Brown Boston^ ${ }^{\wedge} \mathrm{MA}$ MA; 1994.

11. Angheloiu GO, Saul M, Edelman K, Shah H, Mezu UL, Saba S. Pre- 
dictors of left ventricular function deterioration in patients with left bundle branch block and ejection fraction $>50 \%$. Congest Heart Fail. 2013;19(4):E1-4.

12. Barrett-Connor E, Giardina EG, Gitt AK, Gudat U, Steinberg HO, Tschoepe D. Women and heart disease: the role of diabetes and hyperglycemia. Arch Intern Med. 2004;164(9):934-42.

13. Second Joint Task Force of E. Prevention of coronary heart disease in clinical practice Recommendations of the Second Joint Task Force of European and other Societies on Coronary Prevention. Eur Heart J.1998;19(10):1434-503.

14. American Diabetes A. Diagnosis and classification of diabetes mellitus. Diabetes Care. 2008;31 Suppl 1:S55-60.

15. Hurst JW, Morris DC, Alexander RW. The use of the New York Heart Association's classification of cardiovascular disease as part of the patient's complete Problem List. Clin Cardiol. 1999;22(6):385-90.

16. Xiao HB, Lee CH, Gibson DG. Effect of left bundle branch block on diastolic function in dilated cardiomyopathy. Br Heart J. 1991;66(6):443-7.

17. Boineau JP. Diagnosis of multiple infarcts from complex electrocardiograms during normal rhythm, left bundle-branch block, and ventricular pacing. J Electrocardiol. 2011;44(6):605-10.

18. Zhou Q, Henein M, Coats A, Gibson D. Different effects of abnormal activation and myocardial disease on left ventricular ejection and filling times. Heart. 2000;84(3):272-6.

19. Brunekreeft JA, Graauw M, de Milliano PA, Keijer JT. Influence of left bundle branch block on left ventricular volumes, ejection fraction and regional wall motion. Neth Heart J. 2007;15(3):89-94.

20. Li ZB, Wachtell K, Okin PM, Gerdts E, Liu JE, Nieminen MS, et al. Association of left bundle branch block with left ventricular structure and function in hypertensive patients with left ventricular hypertrophy: the LIFE study. J Hum Hypertens. 2004;18(6):397-402.

21. Stergiou GS, Salgami EV, World Health Organization-International Society of H, Usa Joint National Committee on Prevention DE, Treatment of High Blood P, European Soceity of HypertensionEuropean Society of C. New European, American and Interna- tional guidelines for hypertension management: agreement and disagreement. Expert Rev Cardiovasc Ther. 2004;2(3):359-68.

22. Schneider JF, Thomas HJ, Kreger BE, McNamara PM, Kannel WB. Newly acquired left bundle-branch block: the Framingham study. Ann Intern Med.1979;90(3):303-10.

23. Hunt SA, Abraham WT, Chin MH, Feldman AM, Francis GS, Ganiats TG, et al. ACC/AHA 2005 Guideline Update for the Diagnosis and Management of Chronic Heart Failure in the Adult: a report of the American College of Cardiology/American Heart Association Task Force on Practice Guidelines (Writing Committee to Update the 2001 Guidelines for the Evaluation and Management of Heart Failure): developed in collaboration with the American College of Chest Physicians and the International Society for Heart and Lung Transplantation: endorsed by the Heart Rhythm Society. Circulation. 2005;112(12):e154-235.

24. Bavelaar-Croon CD, Wahba FF, Van Hecke MV, Atsma DE, Stokkel MP, Pauwels EK, et al. Perfusion and functional abnormalities outside the septal region in patients with left bundle branch block assessed with gated SPECT. QJ Nucl Med.2001;45(1):10 8-14.

25. Bella JN, Palmieri V, Roman MJ, Paranicas MF, Welty TK, Lee ET, et al. Gender differences in left ventricular systolic function in American Indians (from the Strong Heart Study). Am J Cardiol. 2006;98(6):834-7.

26. Wierzbowska-Drabik K, Krzeminska-Pakula M, Kurpesa M, Trzos E, Rechcinski T, Wejner-Mik P, et al. Impact of gender on left ventricle function in postmenopausal women and age-matched men: analysis of echocardiographic parameters in healthy participants and patients with coronary artery disease. Menopause. 2010;17(3):560-5.

27. Celentano A, Palmieri V, Arezzi E, Mureddu GF, Sabatella M, D Minno G, et al. Gender differences in left ventricular chamber and midwall systolic function in normotensive and hypertensive adults. J Hypertens. 2003;21(7):1415-23. 